\title{
Ground-based and shipborne lidar studies of aerosol fields of the atmosphere above Lake Baikal
}

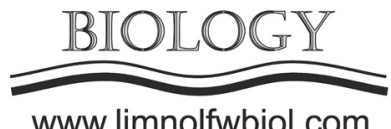

www.limnolfwbiol.com

\author{
Nasonov S.V.*, Balin Yu.S., Klemasheva M.G., Kokhanenko G.P., Penner I.E. \\ V.E. Zuev Institute of Atmospheric Optics of Siberian Branch of the Russian Academy of Science, Academician Zuev Square 1, Tomsk \\ 634055, Russia
}

ABSTRACT. The paper presents the results of lidar experiments to study the atmosphere above Lake Baikal. The measurements were carried out using aerosol-Raman lidars of the LOSA series developed by the Atmospheric Optical Sensing Group of the Institute of Atmospheric Optics.

Keywords: Lake Baikal, aerosol, lidar, forest fires, research vessel "Akademik V.A. Koptyug,” Boyarsky stationary station

\section{Introduction}

Lake Baikal is one of the most important natural complexes in Siberia. The problem of protecting the nature of this object is of global importance. Studies of aerosol fields of the atmosphere rank a special place in the study and protection of the environment of Lake Baikal. An aerosol is one of the most important components of the atmosphere. It plays an important role in changing the optical state of the atmosphere, which in turn affects the radiation balance and, consequently, the Earth's climate. Regional factors affect the aerosol formation: the lay of the land, plant cover, etc. Increased atmospheric pollution by aerosol impurities can be caused both by natural extreme situations (forest fires, volcanic eruptions and dust storms) and anthropogenic impact on the environment (industrial emissions, accidents at chemically and radiation hazardous facilities).

The paper gives a brief description of the features of lidar systems used to study the vertical structure of aerosol fields in the mountain basin of Lake Baikal. The experiments are regularly carried out in the summer, in the coastal zone of the southern part of Lake Baikal, at the Boyarsky stationary station $\left(51.84^{\circ} \mathrm{N}, 106.06^{\circ} \mathrm{E}\right)$ (Zayakhanov et al., 2019). The studies are conducted both in a clear atmosphere (background) conditions and when the atmosphere is polluted with smoke from forest fires in Siberia. The results of combined shipborne research carried out in 2018 and 2019 using the research vessel "Akademik V.A. Koptyug" are discussed. The LOSA-A2 lidar and local control systems were installed on the vessel (Khodzher et al., 2019).

\section{Instrumentation and methods}

Remote lidar methods are the most effective for solving the problems of operational detection and identification of aerosol fields of the atmosphere due to the ability to monitor large areas.

In the experiments, the technical capabilities of the LOSA-M2 aerosol-Raman lidar with two laser radiation wavelengths, $\lambda_{1}=1064 \mathrm{~nm}$ and $\lambda_{2}=532$ $\mathrm{nm}$, were used (Balin et al., 2011). Elastic backscattered radiation was received in the analog mode at these wavelengths and at a shifted wavelength, $\lambda_{3}=607$ $\mathrm{nm}$, of spontaneous Raman scattering, in the photon counting mode. The measurements are carried out around the clock; therefore, it is possible to investigate both the daily spatial and temporal dynamics of the altitude distribution of the aerosol and its transformation during a change in air masses.

During the 2018 expedition to Lake Baikal, a new modification of the LOSA series mobile lidars, the LOSA-A2 lidar, with improved technical characteristics, was tested (Khodzher et al., 2019). A laser operating at a wavelength of $1064 \mathrm{~nm}$ and $532 \mathrm{~nm}$, with a frequency of $20 \mathrm{~Hz}$, was used as a lidar transmitter. The lidar receiving system was made in the form of two identical aspherical lenses with a diameter of $110 \mathrm{~mm}$. They are located symmetrically relative to the optical axis of the transmitter. One of these lenses is designed to detect lidar signals in the visible range. The second receiving lens is designed to register backscattered radiation at a wavelength of $1064 \mathrm{~nm}$. Separate registration of backscattered radiation by two receiving lenses makes it possible to carry out polarization measurements with high energy potential.

*Corresponding author.

E-mail address: nsvtsk@gmail.com (S.V. Nasonov) 
The research was focused on the study of temporary changes in the vertical structure of aerosol fields and the identification of the physical mechanisms of their formation. A general preliminary interpretation of atmospheric laser sounding data is based on an analysis of vertical sections of aerosol fields of the troposphere evaluated in units of the scattering ratio:

$$
R(\lambda, z)=\left(\beta^{\mathrm{a}}(\lambda, \mathrm{z})+\beta^{\mathrm{m}}(\lambda, \mathrm{z})\right) / \beta^{\mathrm{m}}(\lambda, \mathrm{z}),
$$

where ${ }^{\beta} \mathrm{a}(\lambda, \mathrm{z})$ and ${ }^{\beta} \mathrm{m}(\lambda, \mathrm{z})$ are the aerosol and molecular backscattering coefficients at the $\lambda$ wavelength.

\section{Results and discussion}

An analysis of the spatio-temporal patterns of the aerosol fields of the atmosphere revealed the characteristic features of the transport and propagation of aerosol in the atmospheric boundary layer of the mountain basin. The studies were carried out depending on meteorological conditions during observations and orography of the area. Typical altitude structure of aerosol fields in summer above Lake Baikal is a certain stable altitudinal separation into several aerosol layers due to the specific features of air circulation in the mountain basin.

We have obtained a two-dimensional map of the spatial distribution of aerosol impurities above the water area of Lake Baikal. This map illustrates the main areas with a high concentration of pollutants in the air. Anthropogenic sources in areas with high tourist load (Listvyanka and Olkhon Island) and industrial centers (Baikalsk and Severobaykalsk) make the largest contribution to the increased aerosol concentration in the atmosphere.

On some days of the expedition, we recorded an abnormally large amount of smoke aerosol resulted from forest fires in the Siberian region. At this time, the aerosol concentration in the lower one-kilometer layer of the atmosphere was three times higher than the background values. The atmospheric situation reached a smog state. This was caused by the action of an anticyclone that passed over the region from the northwest to southeast, which brought air masses from the north and west, with a large amount of smoke aerosol from forest fires.

This work was supported by the Russian Foundation for Basic Research (Grant No. 18-55-81001).

\section{References:}

Balin Yu.S., Bairashin G.S., Kokhanenko G.P. et al. 2011. LOSA-M2 aerosol Raman lidar. Quantum Electronics 41: 945-949. DOI: 10.1070/ QE2011v041n10ABEH014574

Khodzher T.V., Zhamsueva G.S., Zayakhanov A.S. et al. 2019. Ship-based studies of aerosol-gas admixtures over Lake Baikal basin in summer 2018. Atmospheric and Oceanic Optics 32: 434-441. DOI: 10.1134/S1024856019040067

Zayakhanov A.S., Zhamsueva G.S., Tsydypov V.V. et. al. 2019. Specific features of transport and transformation of atmospheric aerosol and gas admixtures in the coastal zone of Lake Baikal. Atmospheric and Oceanic Optics 32: 158-164. DOI: $10.1134 /$ S1024856019020192 